\title{
Processing of WC/W composites for extreme environments by colloidal dispersion of powders and SPS sintering
}

\author{
E.M. Garcia-Ayala ${ }^{\mathrm{a}}$, S. Tarancon ${ }^{\mathrm{b}}$, Z. Gonzalez ${ }^{\mathrm{a}}$, B. Ferrari ${ }^{\mathrm{a}}$, J.Y. Pastor ${ }^{\mathrm{b}}$, A.J. Sanchez-Herencia ${ }^{\mathrm{a}, *}$ \\ ${ }^{a}$ Instituto de Cerámica y Vidrio, CSIC, Calle Kelsen 5, Madrid, Spain \\ ${ }^{\mathrm{b}}$ Departamento de Ciencia de Materiales-CIME, Universidad Politécnica de Madrid, C/Professor Aranguren s/n, 28040 Madrid, Spain
}

\begin{abstract}
A B S T R A C T

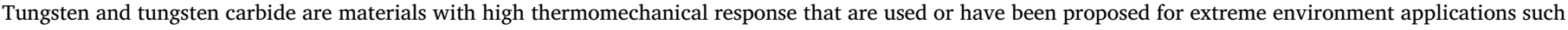

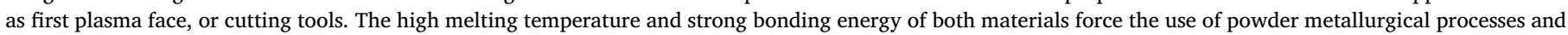

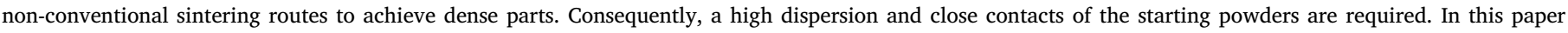

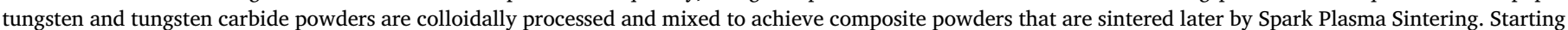

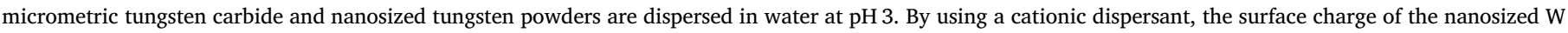

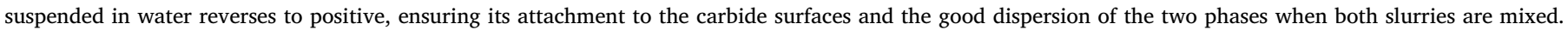

Composite powders with volumetric rations of 50WC/50W, 80WC/20W and 90WC/10W as well as pure WC and W are sintered by SPS following the dimensional

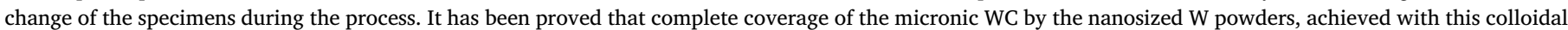

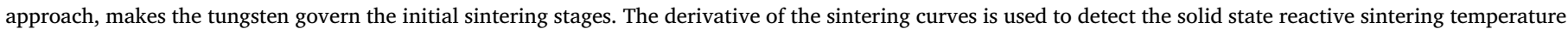

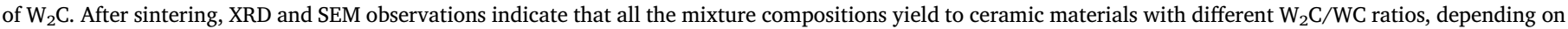

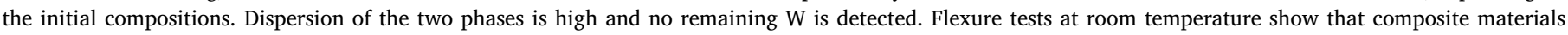
present a slightly lower fracture strength than pure WC.
\end{abstract}

\section{Introduction}

Tungsten and tungsten alloys have been the focus of considerable attention because they have been selected as appropriate materials for several components within future fusion reactors. For example, in the future demonstration nuclear fusion reactor (DEMO) as first wall in the divertor baffle area [1-4]. The first wall materials in the nuclear fusion reactors are a major development challenge as they are exposed to strong high-energy neutron fluxes $(14 \mathrm{MeV})$ and high temperature gradients. It is in this context where the high melting point $\left(3420^{\circ} \mathrm{C}\right)$ and high density $\left(19,3 \mathrm{~g} / \mathrm{cm}^{3}\right)$ stand out as an alternative. These physical characteristics are originated from its position in the group VI of the periodic table, sharing with $\mathrm{U}, \mathrm{Re}, \mathrm{Pt}$, Ir, and Os to be the densest elements [5], and from the strong unsaturated covalent bonds between the valence $5 \mathrm{~d}$ orbitals, which provide metallic tungsten the largest cohesive energy of all the pure elements (7,9-10,09 eV/atom), including diamond (carbon). In fact, tungsten is considered the most ceramic of the metals, as it is a refractory metal with a low thermal expansion coefficient $\left(4,3 \times 10^{-6} /{ }^{\circ} \mathrm{C}\right)$.

Tungsten carbide has also a high melting point $\left(2785^{\circ} \mathrm{C}\right)$, high hardness at room (20-25 GPa) and high temperature, low friction coefficient and good electrical and thermal conductivity. If compared to
W and its alloys, WC has a higher flexural strength, as well as better high temperature creep properties, considering its high temperature hardness. Additionally, WC presents a considerably slower oxidation kinetics than $\mathrm{W}$ [6]. These properties under extreme conditions due to its ceramic conditions, has made tungsten carbide become a better and safer alternative of use for some nuclear applications [7]. In the W - C composition line there is a semicarbide specie between the $\mathrm{W}$ and the WC. The $\mathrm{WC}_{0,5}$ (normally named $\beta-\mathrm{W}_{2} \mathrm{C}$ ) presents a hexagonal compact (hcp) metal sublattice [8,9]. This specie is not thermodynamically stable at room temperature, but rapid cooling and non-equilibrium systems allow its existence and characterization at room temperature $[10,11]$. Tungsten semicarbide shows similar characteristic than tungsten and tungsten carbide like the high melting point $\left(2730^{\circ} \mathrm{C}\right)$, high density $\left(15,8 \mathrm{~g} \mathrm{~cm}^{-3}\right)$ and hardness.

Due the high melting point of both materials powder metallurgy processing techniques have to be considered for shaping instead of technologies from melt. But the high cohesive energy of tungsten and the covalent bond strength of tungsten carbides make very difficult the powders to sinter near to full density [12]. Additionally, since both materials are sensitive to oxidation with temperature, they have to be sintered under protective atmosphere or vacuum [13]. Conventional sintering processes require of high temperatures, in the order of

\footnotetext{
* Corresponding author.

E-mail address: ajsanchez@icv.csic.es (A.J. Sanchez-Herencia).
} 


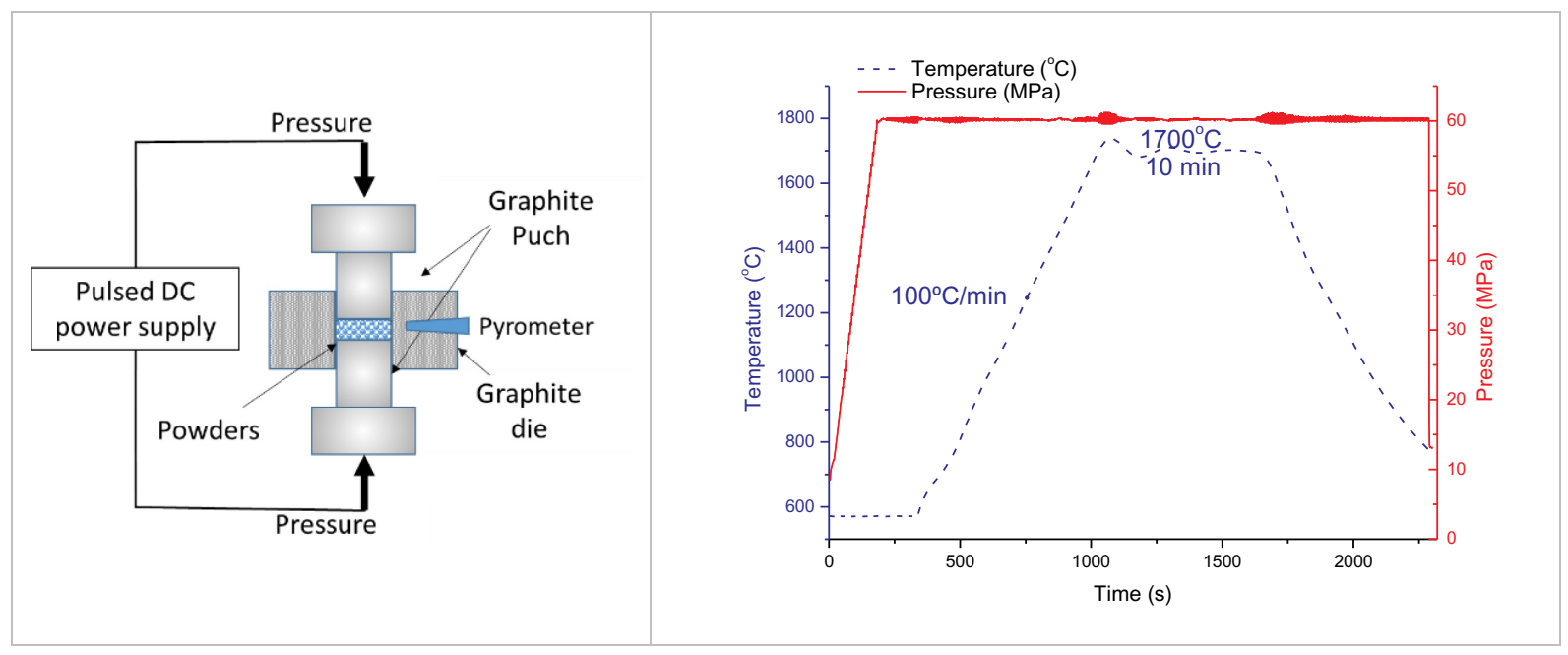

Fig. 1. Scheme of SPS machine and thermal cycle of WC-W mixtures.

$2800{ }^{\circ} \mathrm{C}$, with long dwell periods resulting in coarse microstructures. To achieve high densities without using drastic conditions, some sintering strategies has been developed. The use of metal or ceramic additives [14,15], nanosized powders [16] or non-conventional methods [17-19] have been used to lower the sintering temperatures and increase the density in both tungsten and tungsten carbide. As ceramic additives, among other non-oxides [20,21], the dispersion of tungsten carbide inside tungsten matrices and other sources of carbon, has been considered a way to improve the densification, achieving a high density and fine grain size $[22,23]$ at the same time. Additionally, the presence of tungsten carbide inside pure tungsten compact removes the remaining oxides during field assisted sintering process [24].

Powder metallurgical processing techniques need an intimate mixture of the different phases, especially if they evolve the reaction between the phases, to avoid incomplete reactions and the presence of defects. In this sense, the use of colloidal routes to achieve a high dispersion of the phases has proved its efficiency in $\mathrm{Ti}(\mathrm{C}, \mathrm{N}) / \mathrm{FeNi}$ cermet materials with both high and low metal contents [25,26], as well as in other metals [27]. The use of water as processing media presents evident economic and environmental advantages and also colloidal ones, as water is the universal solvent with a high dielectric constant and dipole momentum. But the use of water for dispersing non oxide materials arises with new challenges that were faced from a physico-chemical point of view. The corrosion and dissolution of the reactive particles in the oxidizing aqueous media was faced by selecting the passivation conditions for processing $[28,29]$ and the appropriate use of dispersants, like the cationic PEI which has proved to be very useful to keep non oxide particles in suspensions. Additionally, by using the colloidal approach, the processing and synthesis of complex structures like the Functional Graded Materials (FGM's) or dispersions of nanoparticles [30,31] have been possible.

In paper it is aimed the fabrication of WC and nanosized $\mathrm{W}$ composite powders by a colloidal route in water. As far as the high dispersion of the powders is ensured, it will be possible to sinter by Spark Plasma Sintering (SPS) to achieve dense ceramic materials composed of tungsten carbide and semi carbide with high dispersion of the two phases.

\section{Experimental}

Commercial powders of metallic tungsten W Grade-D provided by H. C. Starck (Germany) and tungsten carbide WC-040 provided by Hyperion Materials \& Technologies (Spain), were used as starting powders. Particle size and specific surface area were determined with a laser diffraction analyzer (Mastersizer S, Malvern Instruments Ldt., UK) and by one-point $\mathrm{N}_{2}$ adsorption (Monosorb Surface Area, Quantachrome Corporation, USA) respectively. Density of the mentioned powders was measured using a Monosorb Multipycnometer (Quantachrome Corporation, USA).

Zeta potential was determined using a Zetasizer Nano ZS equipment (Malvern Panalytical, United Kingdom) based on Phase Analysis Light Scattering (PALS) technology. For measurements, the powders were suspended in $10^{-2} \mathrm{~N} \mathrm{KCl}$ media at a solid concentration of $1 \mathrm{~g} / \mathrm{L} . \mathrm{pH}$ was modified with $\mathrm{HCl}$ and Tetramethylammonium Hydroxide additions to acid and basic values prior to powder additions. Polyethyleneimine (PEI, M.W.: 2000, Sigma Aldrich), used as dispersant, was added at a fixed $\mathrm{pH}$ prior to the powder additions. $\mathrm{pH}$ was readjusted after the powder addition.

High solid content suspensions (30\% vol. solids content) were prepared using deionized water as a dispersion medium. The $\mathrm{W}$ slurries were prepared by adding the powders to the water with the selected amount of dispersant and fixing the $\mathrm{pH}$ at 3 with $\mathrm{HCl}$. Suspensions of WC powders were prepared by following the same procedure but removing the addition of PEI step. Both $\mathrm{W}$ and WC suspensions were mechanically stirred separately for $15 \mathrm{~min}$ and then mixed together, being milled for $2 \mathrm{~h}$ by using silicon nitride balls. By following this previous method, three different compositions were formulated, varying the volumetric proportion of WC and W: $90 \% \mathrm{WC}-10 \% \mathrm{~W}, 80 \%$ WC-20\%W and $50 \% \mathrm{WC}-50 \% \mathrm{~W}$. After milling the suspensions were dried by rotatory evaporation. The processed mixture of powders was crushed in an agate mortar prior to SEM characterization and sintering.

Powders were sintered by Spark Plasma Sintering (SPS), using a Dr. Sinter, SPS-510 CE; Fuji Electronic Industrial Co., Ltd., (Japan) with a $30 \mathrm{~mm}$ of diameter graphite die and graphite punches. Parameters for this thermal cycle were settled with a pressure of $60 \mathrm{MPa}$ with heating and cooling rates of $100^{\circ} \mathrm{C} / \mathrm{min}$ and a dwell temperature of $1700^{\circ} \mathrm{C}$ for $10 \mathrm{~min}$, following the scheme presented in Fig. 1. Displacement of punches was recorded during the sintering experiments and temperature was controlled by an optical pyrometer which started to detect temperature of the sample at $587^{\circ} \mathrm{C}$.

Dimensional change during sintering of the sample vs time was extracted from the displacement data and differentiate time was calculated as the average of the slopes between a given time and its two closest neighbors. Density of the sintered pieces was measured in ethanol by the Archimedes' method according to the ASTM C373-88 standard.

XRD was recorded in powders and sintered samples by using a Siemens-Bruker D8 Advance Diffractometer (Germany) using $\mathrm{Cu} \mathrm{K}_{\alpha}$ radiation $(\lambda=1,540,598$ Angstrom). The diffraction patterns were measured step by step $\left(0,05^{\circ}\right.$ and $0,02^{\circ}$ in $\left.2 \theta\right)$ in a $2 \theta$ range from 10 to 
Table 1

Characteristics data for the as received $\mathrm{W}$ and WC powders.

\begin{tabular}{llllll}
\hline & $\rho(\mathrm{mg} / \mathrm{L})$ & $\begin{array}{l}\mathrm{SSA} \\
\left(\mathrm{m}^{2} / \mathrm{g}\right)\end{array}$ & $\mathrm{d}_{\mathrm{BET}}(\mu \mathrm{m})$ & $\begin{array}{l}\text { Particle size } \\
(\mu \mathrm{m})\end{array}$ & $\begin{array}{l}\text { Agglomeration factor } \\
(\mathrm{af})\end{array}$ \\
\hline W & 19,3 & 2,58 & 0,12 & $\begin{array}{l}1,24 \\
12,22\end{array}$ & $\begin{array}{l}10 \\
100 \\
7,90\end{array}$ \\
WC & 15,6 & 0,14 & 2,75 & 7,90 & 3 \\
\hline
\end{tabular}

$70^{\circ}$. JCPDS files 004-0806, 025-1047 and 035-0776 were used to identify $\mathrm{W}, \mathrm{WC}$, and $\mathrm{W}_{2} \mathrm{C}$ respectively.

SEM analysis was made on samples polished with diamond paste down to $1 \mu \mathrm{m}$ and chemically etched by the Murakami method. The equipment used was a field emission scanning electron microscopy from Auriga Series (FE-SEM Zeiss, Oberkochen, Germany) with energy dispersive X-Ray spectroscopy (EDX, X-Flash detector 5010, Bruker, Germany).

For mechanical test the sintered samples were cut in $3,5 \times 2 \mathrm{~mm}$ beams using a refrigerated electro-discharge machining. A three-point bending tests at a temperature of $25^{\circ} \mathrm{C}$ was performed using a universal testing machine (Instron 8501, High Wycombe, United Kingdom) with $20 \mathrm{~mm}$ of span.

\section{Results and discussion}

\subsection{Starting powders characterization}

Main characteristics of starting powders are summarized on Table 1. Specific surface area by BET approach and helium pycnometric density were used to determine the theoretical diameter of the particles $\left(\mathrm{d}_{\mathrm{BET}}\right)$ supposing spherical. This approach indicated that tungsten particles are in the nanometric range $(120 \mathrm{~nm})$ while tungsten carbide particles have a particle diameter almost two order of magnitude superior $(2,75 \mu \mathrm{m})$.

Fig. 2a shows the particle size distribution directly measured by a laser diffraction technique for both powders suspended in water. It can be seen that WC presents a monomodal particle size distribution centered on $7,90 \mu \mathrm{m}$ which corresponds to an agglomeration factor of 3 . For the metallic W, it can be observed a bimodal distribution of particles with two peaks centered at $1,24 \mu \mathrm{m}$ and $12,22 \mu \mathrm{m}$, which corresponds to agglomeration factors of 10 and 100 respectively (data also included in Table 1).

$\mathrm{XRD}$ of the WC and $\mathrm{W}$ powders are presented in Fig. 2b. In both cases, the XRD are indexed to the patterns and do not show the presence of oxides. $\mathrm{W}$ powders showed the presence of the $\mathrm{W}_{2} \mathrm{C}$, probably remaining from the fabrication process [32].

The calculated agglomeration factor for each powder (Table 1) can be clearly observed in the SEM micrograph of the starting powders included in Fig. 2c and d. The differences in particle size of both powders can be clearly appreciated, as well as their different factors of agglomeration. For the metallic tungsten (Fig. 2c), it can be seen the nanosized primary particles forming the agglomerates, while in the case of the WC (Fig. 2d) the particles are within the values reported by the size distribution plot and almost loose one from each other.

\subsection{Dispersion of powders in aqueous suspensions}

The high agglomeration of tungsten and the big differences in the particle size of both powders make the production of materials with an intimate contact of the phases difficult. The requirements of milling to break the tungsten agglomerates and the necessity of an effective mixing with the WC powders requires of the colloidal processes. Both, milling and mixing in water need the development of repulsive interparticle forces without the chemical corrosion and solution of the nonoxide powders. For that reason, the tungsten was dispersed at $\mathrm{pH} 3$ using PEI as a dispersant. The cationic characteristic of the dispersant makes the surface charge change from negative to positive. Fig. 3a shows the zeta potential values for tungsten powders suspended in water with different amounts of PEI. It can be seen that zeta potential value at $\mathrm{pH} 3$ without dispersant is negative $(-70 \mathrm{mV})$. An addition as small as $0,5 \%$ of the cationic polyelectrolyte modifies the particles surface of the powders, changing the sign to positive with a value of $+80 \mathrm{mV}$. After this strong increment, the zeta potential continues to

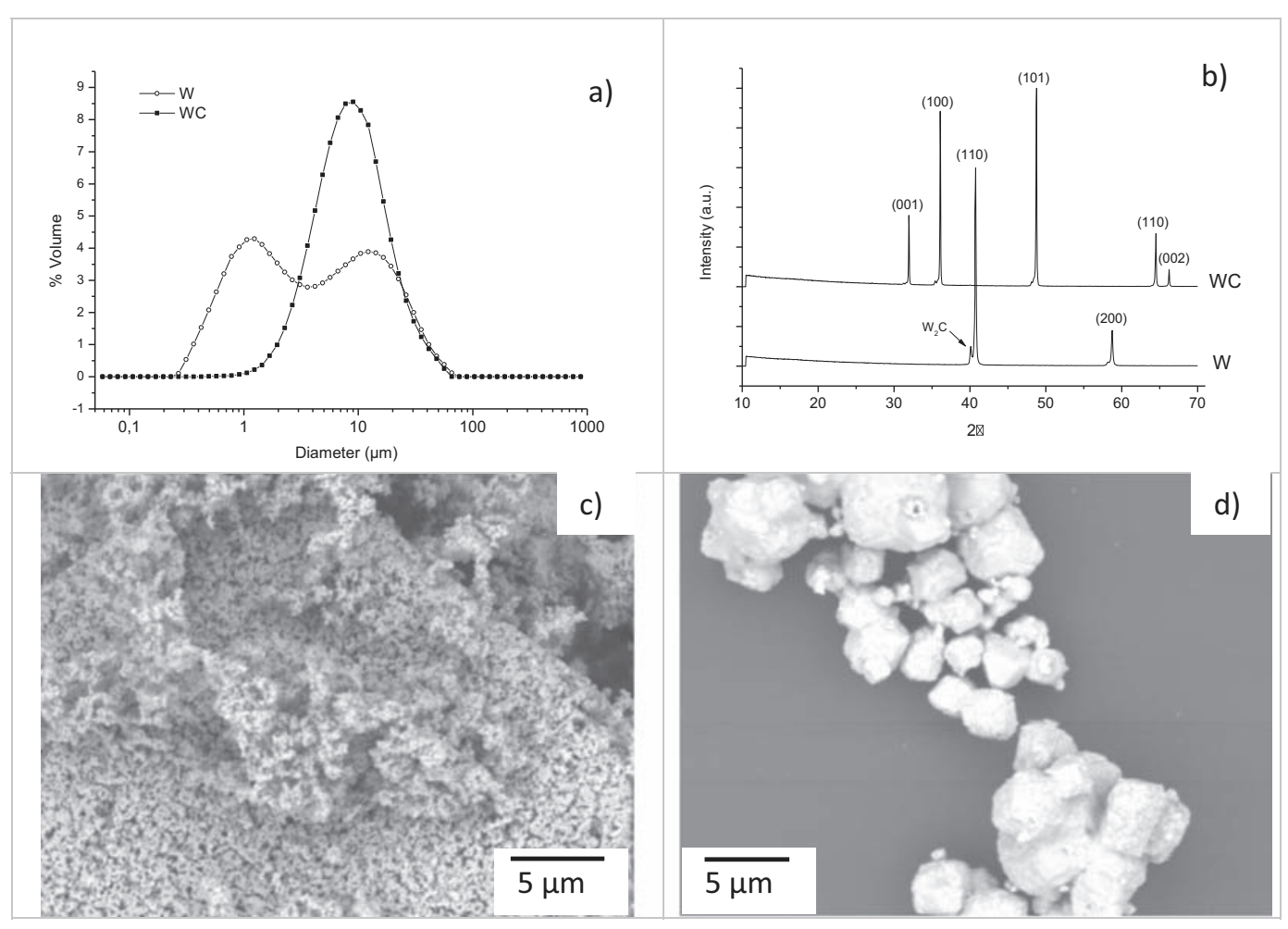

Fig. 2. Particle size distribution (a), XRD pattern (b) and micrographs (c, d) of the as received W and WC powders. 


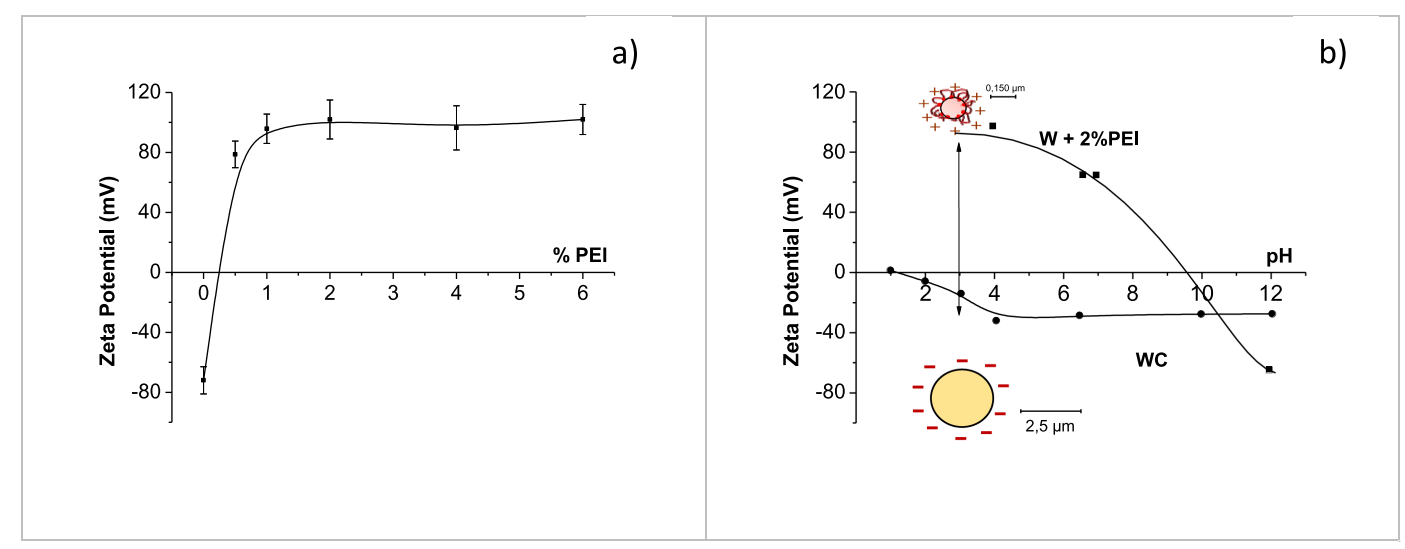

Fig. 3. Zeta potential evolution for the (a) $\mathrm{W}$ powders suspended at $\mathrm{pH}=3$ with the amount of polyethyleneimine (PEI) and (b) for the W powders with 2 wt $\%$ PEI and bare WC powder with the $\mathrm{pH}$.

increase but slowly until a dispersant content of $2 \mathrm{wt} \%$ (referred to powders) is achieved. For higher contents of dispersant, the zeta potential values remain constant indicating that nanosized particles have been completely covered by the polyelectrolyte. Consequently, the selected amount of dispersant to be added to the slurries was $2 \mathrm{wt} \%$. Fig. $3 \mathrm{~b}$ shows the variation of the zeta potential with the $\mathrm{pH}$ for the PEI coated metallic tungsten and for the bare WC (without dispersant). After the surface modification, the metallic tungsten presents an isoelectric point at $\mathrm{pH}$ in between 9 and 10 with positive values at neutral and acidic conditions, while the tungsten carbide show negative zeta potential values at all the pHs recorded [33-35].

Consequently, by this colloidal control of the surfaces charges, when the nanosized particles of metallic tungsten dispersed in water at $\mathrm{pH} 3$ are dropt into the stirred slurry of the WC micronic particles, both at $\mathrm{pH}=3$, the positively charged $\mathrm{W}$ particles are electrostatically attracted to the negatively charged WC and homogeneously coats them, as schematized in Fig. 4.

Fig. 5 shows the SEM micrographs of the mixed WC/W powders with volumetric ratios of 50/50 (a), 80/20 (b) and 90/10 (c) obtained after mixing the slurries in the calculated proportions and drying. It can be seen that metallic tungsten particles are attached to the bigger carbide particles forming a composite powder with a highly homogenous distribution of the phases. In the case of sample 50/50, it is observed that tungsten particles almost cover all the carbide particles, while for the $80 / 20$ and $90 / 10$ composite powders, the tungsten particles are attached to the carbide ones distributed along all the surface.

\subsection{Spark plasma sintering of the composite powders}

The three composite powders colloidally processed as well as pure metallic tungsten and tungsten carbide were sintered by the Spark Plasma Sintering (SPS) technique. During the process, the displacement of the sample was recorded to determine the sintering curves for all the five samples as shown in Fig. 6a. It has to be pointed that only temperatures higher than $570^{\circ}$ could be recorded due to the pyrometer limits. Fig. $6 \mathrm{~b}$ shows the differential of the sintering curves with the time where three characteristic temperatures, that are going to be discussed below, can be identified.

The sintering curve of pure tungsten powder shows the highest final contraction of all the tested materials, about $60 \%$. This high contraction is due to the nanometric size of the powder which has a low cold compressibility ratio. Consequently, the pressure selected for the process yield to a low green density before heating. As the temperature increases, a first shrinkage is observed at $630{ }^{\circ} \mathrm{C}$, indicating that plasticity of tungsten at this temperature allows the powders to rearrange under the pressure to get a better compactation than the one achieved in cold. After this second compactation of the powders, it can be seen that densification process starts at $770{ }^{\circ} \mathrm{C}$. A minimum in the differential curve (identified as $\mathrm{A}$ ) indicates that maximum sintering rate is achieved at $915^{\circ} \mathrm{C}$. Finally, a dimensional plateau is reached over $1500^{\circ} \mathrm{C}$. This plateau indicates that shrinkage is finished, and only grain growth is expected. But the final density achieved with this material is 90 th\%, which is not in concordance with the ending of the

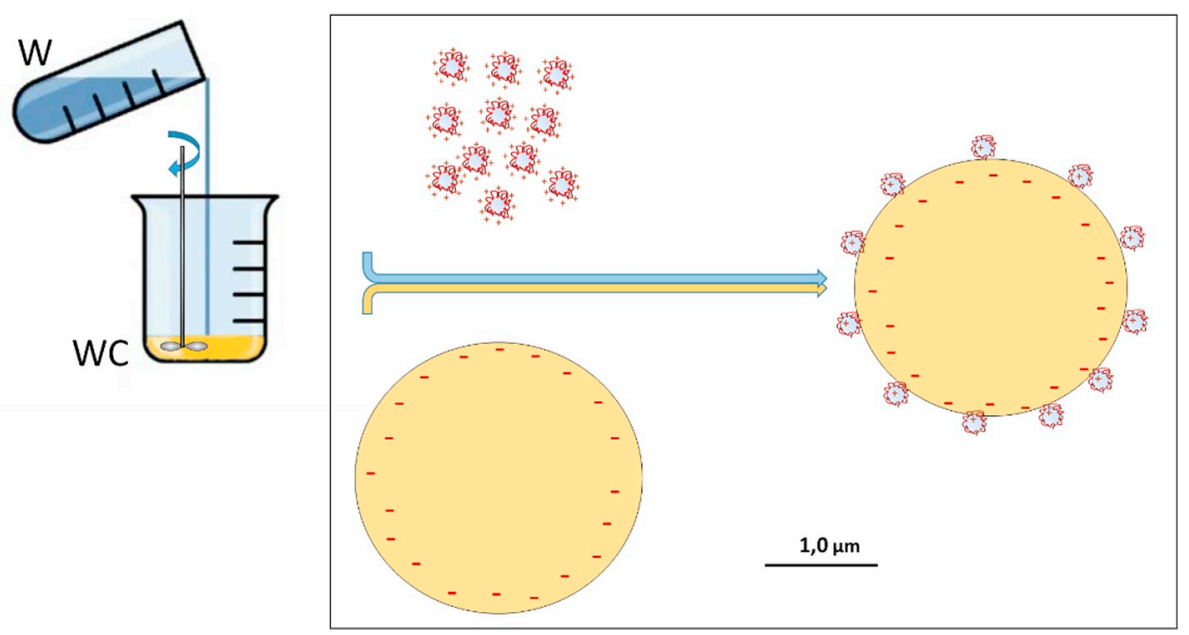

Fig. 4. Scheme of the powders behavior during mixture of slurries. The W nanosized particles, with positive surface charge due to the PEI addition, attach to the negative charged WC particles. 

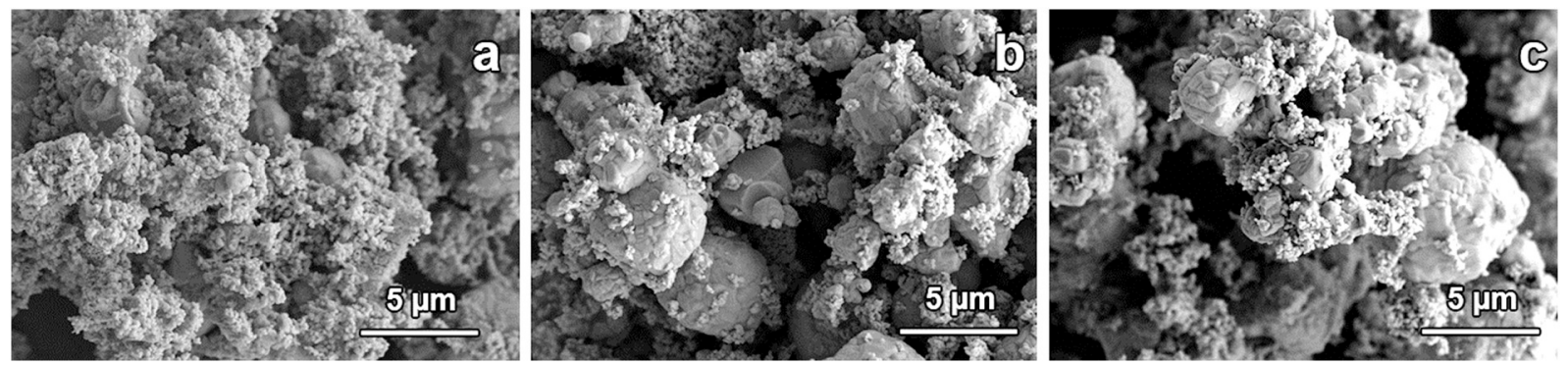

Fig. 5. SEM micrograph of the mixture of powders after drying. In the 50WC/50W composition (a) the W has completely coated the WC, while in the $80 \mathrm{WC} / 20 \mathrm{~W}$ (b) and $90 \mathrm{WC} / 10 \mathrm{~W}(\mathrm{c})$ it can be seen the dispersed nanosized $\mathrm{W}$ attached to the WC particles.

sintering process. This lack in density is due to the reaction of the outer tungsten powders with the graphite that composes the die and punches [19]. This reaction promotes the formation of a dense WC and $\mathrm{W}_{2} \mathrm{C}$ crust that stops any dimensional change of the sample before the end of the densification process, inhibiting the complete densification of the sample. Fig. 7a shows a scheme of this process. Fig. $7 \mathrm{~b}$ shows a cross section of the edge of the sample showing the crust composed of a layer of tabular WC and a layer of equiaxed $\mathrm{W}_{2} \mathrm{C}$. In the $\mathrm{W}_{2} \mathrm{C}$ layer the grain size changes as we approach to the porous pure tungsten area. Finally, Fig. $7 \mathrm{c}$ shows a micrograph at the center of the sample where the spherical pure tungsten grains, with an average size of $15 \mu \mathrm{m}$, and the remaining porosity in the triple points, with pore sizes in the range of $1 \mu \mathrm{m}$, can be observed.

The other extreme of the sintering curves is the $100 \%$ WC sample, which has not completed the contraction process when the maximum temperature is achieved. Shrinkage continues during the $1700{ }^{\circ} \mathrm{C}$ plateau to achieve a final value of $38 \%$ at the end of the plateau. The final density after sintering is 92 th\%. In the differential curve (Fig. 6b) it can be seen that temperature of maximum shrinkage (designated as $\mathrm{C}$ ) is at $1680^{\circ} \mathrm{C}$, very close to the temperature of the sintering plateau where the sample remains for $10 \mathrm{~min}$. Consequently, there is an incomplete sintering of the sample manifested in the low relative density achieved. The microstructure of this sample is shown in Fig. 8. The grain size is about $3 \mu \mathrm{m}$, near to the starting particle size. The porosity on triple points is observed, with pore sizes of also around $3 \mu \mathrm{m}$. Both the small grain size and pores are a consequence of the unfinished sintering.

The other sintering curves corresponding to the composite powders are placed between the two corresponding to pure W and pure WC compositions. In the case of the 50WC/50W composition, the sintering started at the same temperature as in the pure tungsten. The shrinkage corresponding to the first compaction is also observed at $630^{\circ} \mathrm{C}$. Additionally, as happened in the pure $\mathrm{W}$ sample, the densification process starts at $770{ }^{\circ} \mathrm{C}$. These coincidences in characteristic temperatures are because of the smaller tungsten particles have coated the WC bigger ones, making tungsten to govern the first stages of the sintering. After this point, it can be observed in.

Fig. $6 \mathrm{a}$ that $0 \mathrm{WC} / 100 \mathrm{~W}$ and $50 \mathrm{WC} / 50 \mathrm{~W}$ curves move away one of each other, indicating that WC is playing a role in the sintering process. When the heating ramp finishes, the shrinkage is almost ended and no dimensional changes are observed during the plateau, keeping constant the final shrinkage of $47 \%$. The final density of this sample is of 95,8 th $\%$. In the differential curve of the 50WC/50W sample (Fig. 6b), the minimum (A) corresponding to the maximum shrinkage is observed at $930^{\circ} \mathrm{C}$, confirming the main role of the pure tungsten in the sintering. In addition to this minimum, a new minimum (denominated as $\mathrm{B}$ ) is observed at $1250^{\circ} \mathrm{C}$. This has been assigned to the solid state reaction sintering between $\mathrm{W}$ and $\mathrm{WC}$ to produce $\mathrm{W}_{2} \mathrm{C}$. As the reaction occurs, the $\mathrm{W}_{2} \mathrm{C}$ enhances the sintering process and the shrinkage accelerates. Fig. 9a shows the SEM micrograph of the 50WC/50W sample after sintering. It can be seen that it is a dense microstructure of equiaxed grains with average diameter of $7,5 \mu \mathrm{m}$ with remaining intragranular porosity. XRD pattern, included in Fig. 9b, clearly proves that reaction of W and WC has been taking place and, due to the fast cooling rate of the SPS process, it has been kept after cooling. No pure tungsten peaks are detected, and only unreacted WC is observed. It has to be pointed that 50/50 ratio in volume does not correspond to the equimolecular amounts.

In the $80 \mathrm{WC} / 20 \mathrm{~W}$ sample, the pure tungsten does not control the first compaction at $630^{\circ} \mathrm{C}$ any longer, but the presence of tungsten still influences the sintering process and the densification starts sooner than in the pure WC, concisely at $830^{\circ} \mathrm{C}$. Densification process has already finished when the maximum temperature is reached, achieving a final shrinkage of $38,1 \%$. This contraction is kept almost constant during the dwell process. The final density of this sample is of 95,4 th\%.

Differential curve confirms that tungsten has lost its relevance in the sintering process and the previously detected minimum $\mathrm{A}$ has

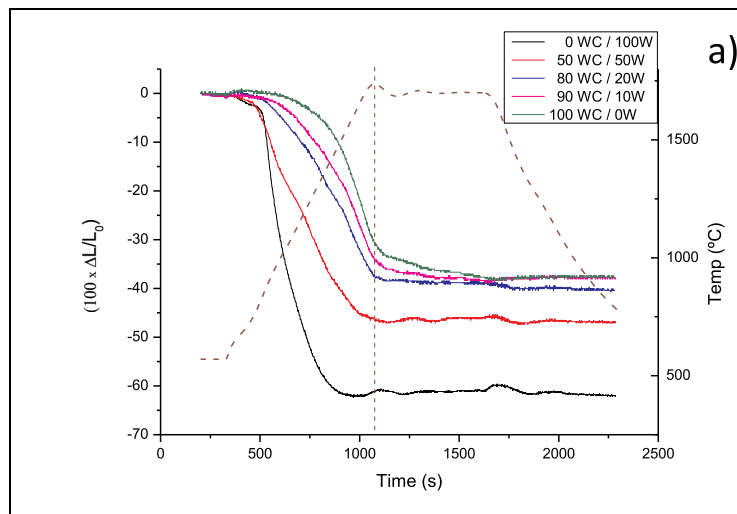

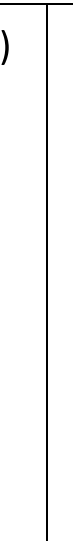

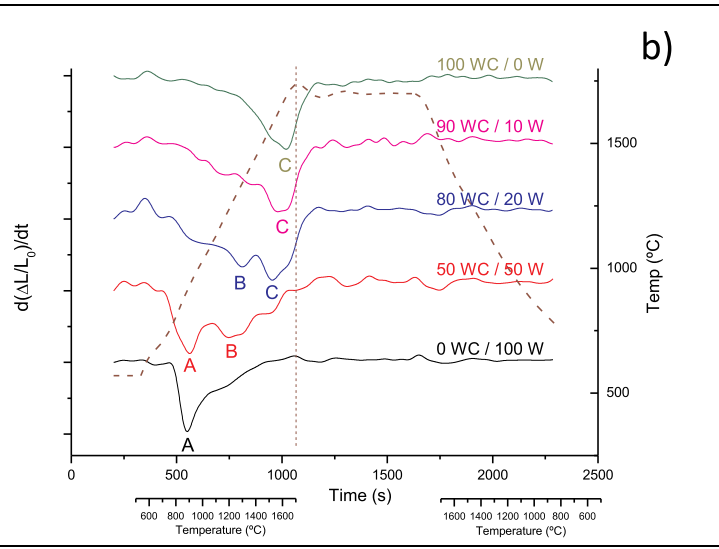

Fig. 6. (a) Curves of dimensional change vs time (sintering curve) recorded during the SPS process of the pure W and WC and the processed composite powders. The differential curve vs time (b), obtained from the previous one indicated some of the characteristic points. 


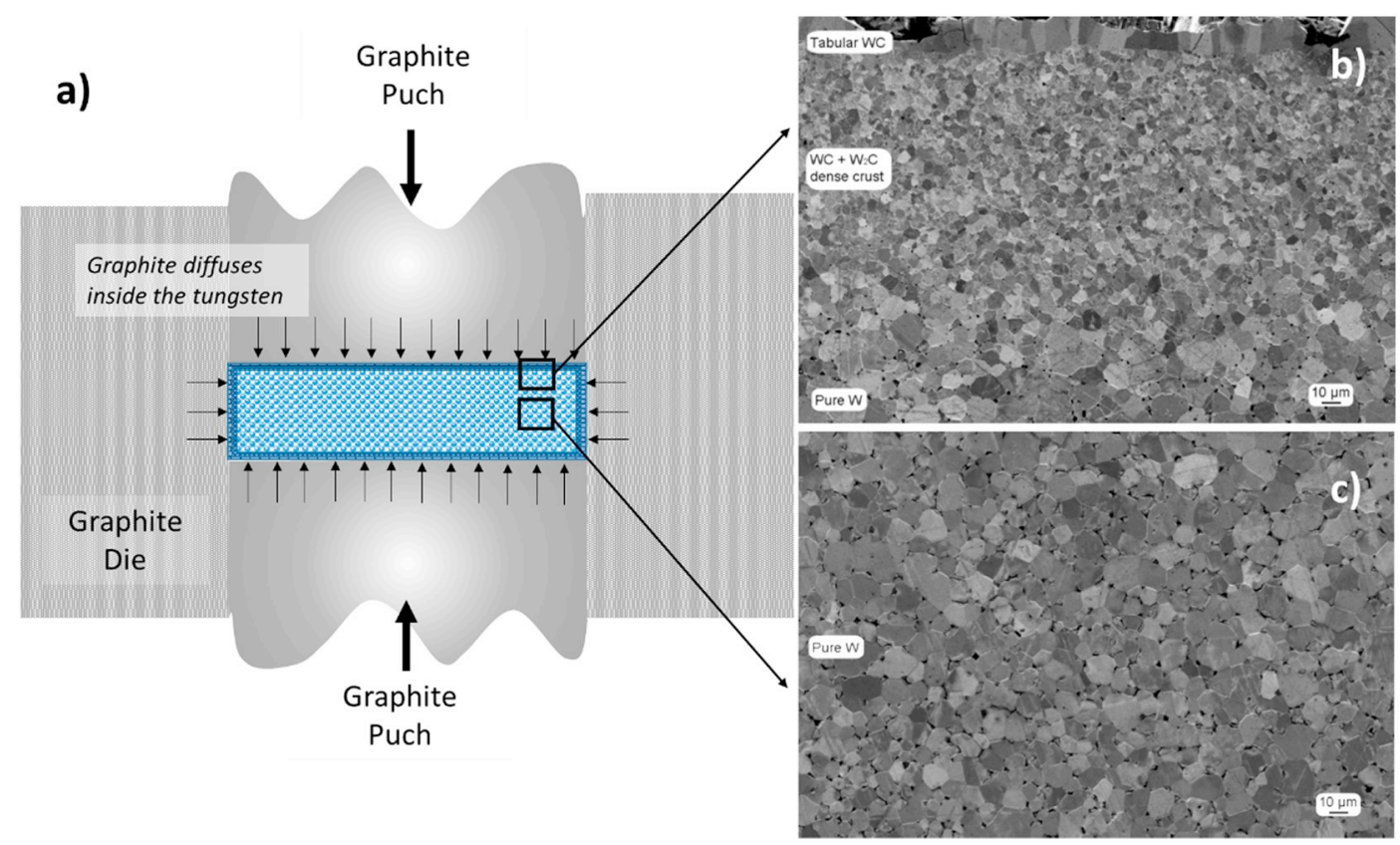

Fig. 7. Scheme of process of the dense carbides crust formation inside the sintering chamber during SPS. (a) The outer carbides dense crust (b) is composed of a tabular WC layer, and equiaxed $\mathrm{W}_{2} \mathrm{C}$. Inside the sample (c) there is pure porous tungsten.

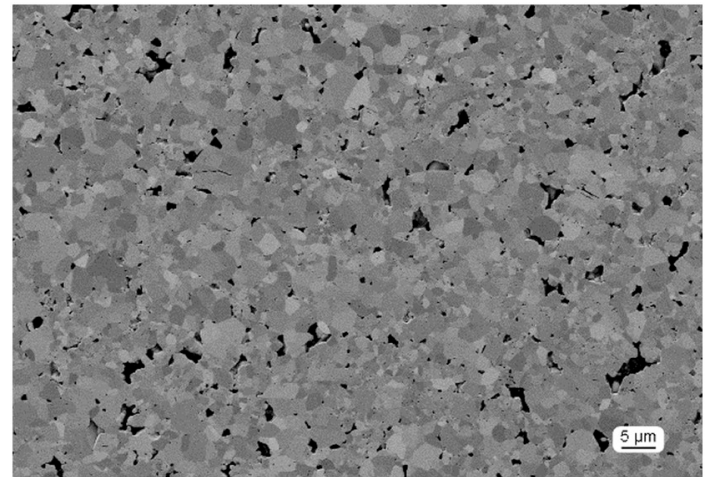

Fig. 8. SEM micrograph on the cross section of a pure WC sintered sample.

disappeared in this sample, but the minimum $\mathrm{B}$, related to the $\mathrm{W}_{2} \mathrm{C}$ formation and sintering, can also be observed at $1330^{\circ} \mathrm{C}$. In this sample, the presence of the minimum $(\mathrm{C})$ starts to be observed corresponding to the densification process of the unreacted WC.
Microstructure of 80WC/20W sintered sample is shown in Fig. 10a. In this micrograph, two types of grains can be seen, one of grains with intragranular spherical porosity that are very similar to those of $\mathrm{W}_{2} \mathrm{C}$ observed in the 50WC/50W sample; and the other type of grains that are smaller in size and does not present intragranular pores, but they define intergranular porosity in triple points. This late kind of grains are assigned to the WC grains that has not reacted with the $\mathrm{W}$ and sinters at higher temperature. As both samples present $\mathrm{W}$ and $\mathrm{C}$, different phases could not be identified by EDX. However, chemical etching can be used to qualitatively identify the phases as the $\mathrm{W}_{2} \mathrm{C}$ grains are faster etched than WC ones. Consequently, the sample shows a topography where the $\mathrm{W}_{2} \mathrm{C}$ grains are in a deeper level than the WC grains. It can be seen that grains of both compositions are homogeneously dispersed along all the sample, confirming the good dispersion of composite mixtures of powders. XRD pattern on the cross section (Fig. 10b) confirms the presence of both phases, indicating that also the $\mathrm{W}_{2} \mathrm{C}$ remains quenched due to the fast cooling of the SPS process.

Finally, the $90 \mathrm{WC} / 10 \mathrm{~W}$ sample presents a sintering behavior closer to the $100 \mathrm{WC} / 0 \mathrm{~W}$ sample. The densification starts at $995^{\circ} \mathrm{C}$, indicating that tungsten still promotes the densification process. But then, when
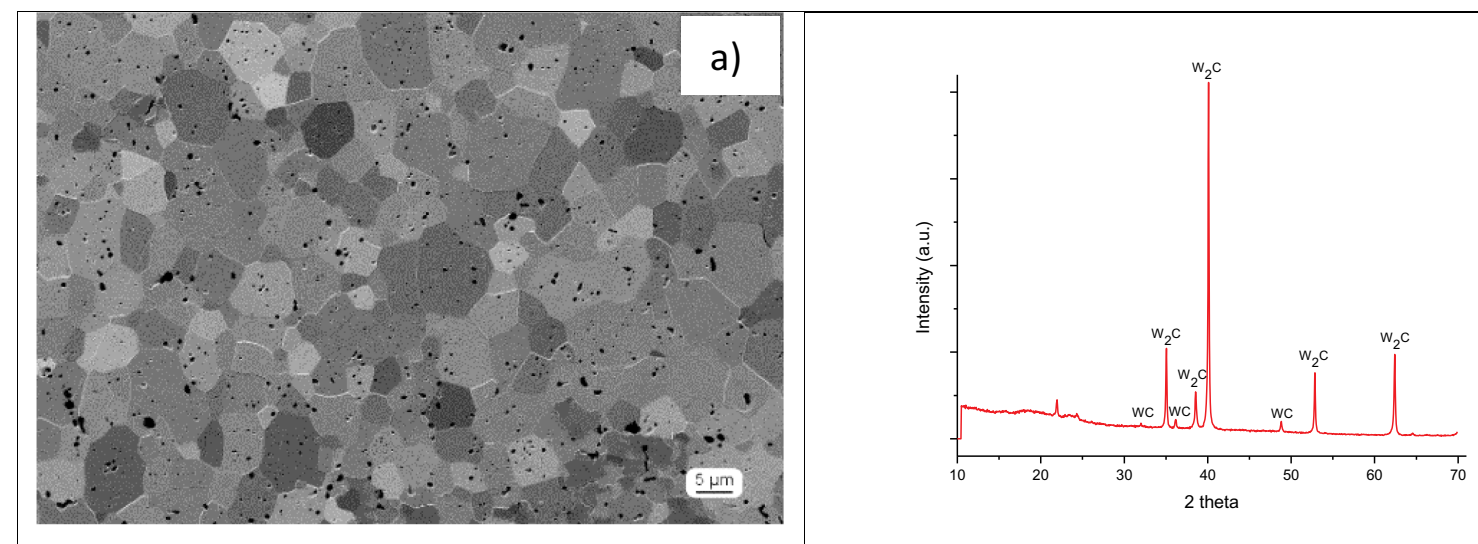

b)

Fig. 9. (a) SEM micrograph on the polished cross section of the 50WC/50W after SPS sintering, showing the intragranular porosity and the equiaxed grains. XRD (b) show that all the $\mathrm{W}$ has reacted to form the $\mathrm{W}_{2} \mathrm{C}$ phase. 


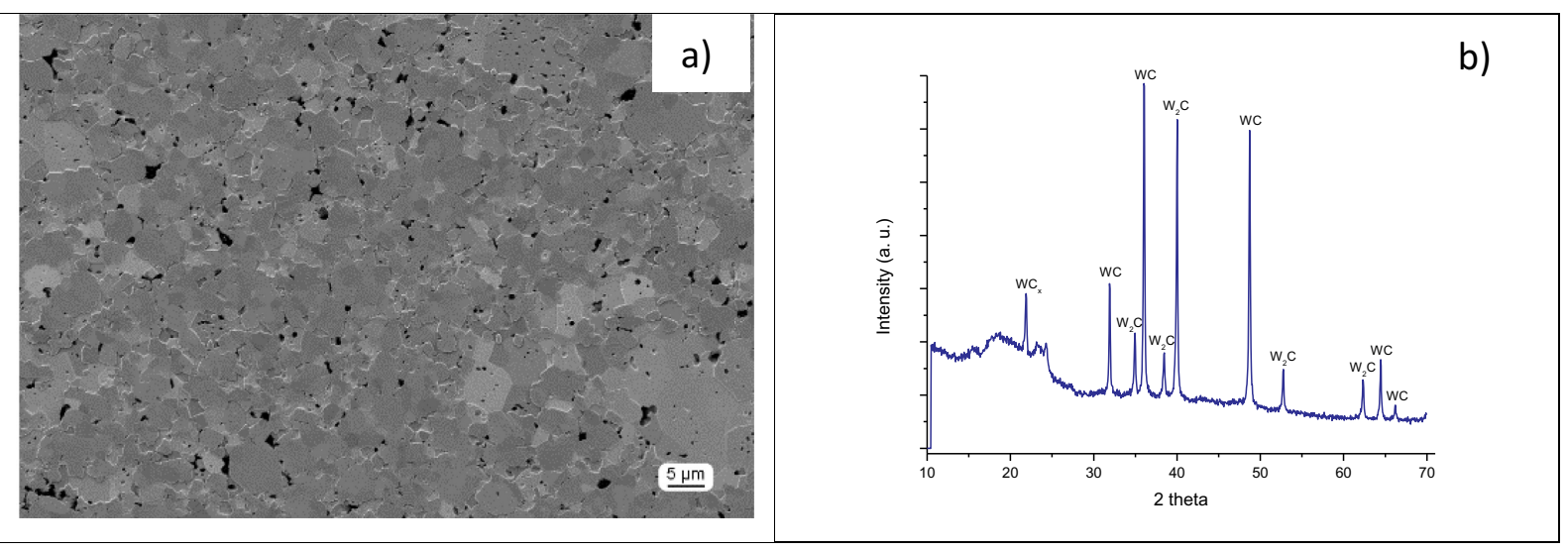

Fig. 10. (a) SEM micrograph on the polished cross section of the $80 \mathrm{WC} / 20 \mathrm{~W}$ after SPS sintering. More etched areas (light gray) corresponds to the $\mathrm{W}_{2} \mathrm{C}$ phase and non-etched (dark gray) to the WC. XRD (b) confirms the presence of both phases.

the dwell temperature is achieved, the densification process has not finished yet and shrinkage continues during the $1700^{\circ} \mathrm{C}$ plateau. Final shrinkage after the plateau is $38 \%$, coincident with the WC value. Final density after sintering is of 95,1 th\%. In the differential curve, the minimum $\mathrm{B}$ corresponding to the $\mathrm{W}_{2} \mathrm{C}$ reaction and sintering is not appreciated. Even when the reactions happen, the amount of $\mathrm{W}_{2} \mathrm{C}$ is very low to control the sintering, which is dominated by the WC. In fact, the unique point clearly detected is the minimum $\mathrm{C}$, corresponding to the maximum sintering rate of the carbide.

Fig. 11a shows a micrograph taken in a transverse section of the $90 \mathrm{WC} / 10 \mathrm{~W}$ sample. As it happened in the $80 \mathrm{WC} / 20 \mathrm{~W}$ sample, the faster chemical etching to the $\mathrm{W}_{2} \mathrm{C}$ allows to distinguish them as they are at a deeper level than WC grains. It can be seen that material microstructure is formed by a WC matrix not completely sintered with irregular porosity in triple points and with the $\mathrm{W}_{2} \mathrm{C}$ grains highly and homogeneously dispersed. XRD (Fig. 11b) shows again the presence of both the phases in the sample. As expected, the amount of $\mathrm{W}_{2} \mathrm{C}$ is smaller than in the other compositions, as the amount of pure $\mathrm{W}$ to react with the carbide is also smaller. No metallic tungsten was detected in any of the three composite samples after sintering.

\subsection{Mechanical properties}

Fracture strength of sintered samples were measured by three points bending test.

Fig. 12 shows the strain-stress curve of the tests for all the compositions. Tests were performed placing the beams in the fixture to apply the load on the cross section. This configuration was selected to assure

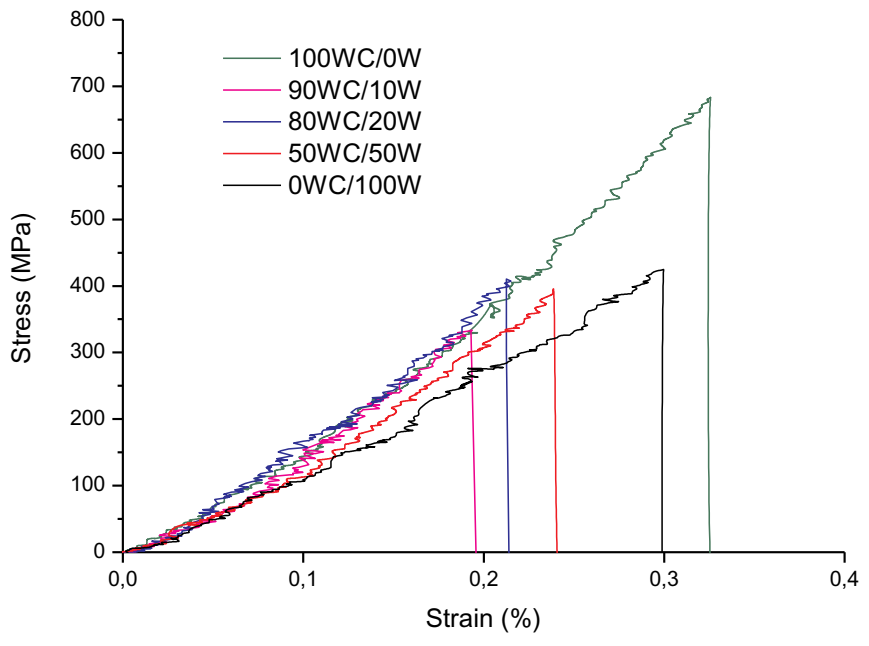

Fig. 12. Strain-Stress plot for the different compositions sintered by SPS recorded in the 3 points bending test at room temperature. Strain-Stress plot for the different compositions sintered by SPS.

that maximum load would be applied on the same zones that have been microstructurally observed.

The maximum flexural resistance is achieved by the pure WC sample. The other four samples present similar fracture values, but it has to be noted that only a sample of each composition has been tested and there are no statistical data to analyze the rupture values.
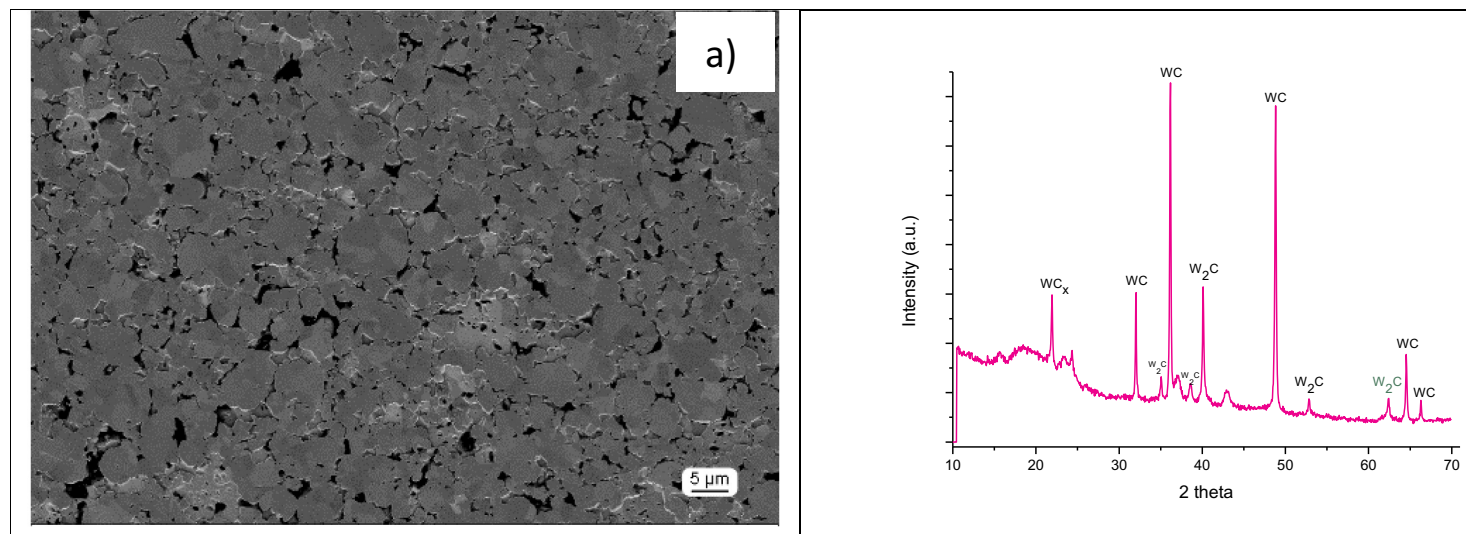

b)

Fig. 11. (a) SEM micrograph on the polished cross section of the $90 \mathrm{WC} / 10 \mathrm{~W}$ after SPS sintering. Light gray zones correspond to the more etched $\mathrm{W}_{2} \mathrm{C}$ phase, while non-etched (dark gray) to the WC. XRD (b) confirms the presence of both phases. 
Consequently, no conclusion can be taken in this aspect. However, it is notable to pay attention to the slope and shape of the strain-stress curves. Regarding to the shape of the curves, a brittle fracture is observed in all the samples. It can be seen that pure tungsten presents a brittle behavior as the plastic to brittle transition is at high temperature, but the slope of the curve is the lower of all the composition as a consequence of the lower elastic modulus of the metal. The 50WC/50W sample, which is mainly composed of $\mathrm{W}_{2} \mathrm{C}$ after sintering, presents a slope higher than pure tungsten, as a consequence of the "ceramization" that $\mathrm{C}$ has produced to the tungsten. The other three samples present higher and similar slope values, as they are mainly ceramic WC. In the $80 \mathrm{WC} / 20 \mathrm{~W}$ and $90 \mathrm{WC} / 10 \mathrm{~W}$ samples, the presence of $\mathrm{W}_{2} \mathrm{C}$ does not have any relevant influence in the observed elastic modulus.

\section{Acknowledgements}

This work is part of the ING4MATER project supported by the Ministerio de Economía y Competitividad of Spain under grants MAT2015-70780-C4-1-P and MAT2015-70780-C4-4-P and the project ADITIMAT-CM founded by the Regional Government of Madrid under grant S2018/NMT-4411.

Dr. Z. Gonzalez acknowledges the Ministerio de Economía y Competitividad of the Spanish Government for the Postdoctoral Fellowship: IJCI-2016-28538.

Ms. E. Macarena García acknowledges the Ministerio de Economía y Competitividad of the Spanish Government for the predoctoral research grant BES-2016-079038.

All projects and financial support are cofounded by the FEDER program of the European Union.

\section{References}

[1] A.F. Rowcliffe, L.M. Garrison, Y. Yamamoto, L. Tan, Y. Katoh, Materials challenges for the fusion nuclear science facility, Fusion Eng. Des. 135 (2018) 290-301, https://doi.org/10.1016/j.fusengdes.2017.07.012.

[2] Y. Wu, E. Stevens, K. Kim, D. Maisonnier, A. Kalashnikov, K. Tobita, D. Jackson, C. Alejaldre, D. Perrault, D. Panayotov, B. Merrill, C. Grisolia, M. Zucchetti, T. Pinna, D. van Houtte, S. Konishi, B. Kolbasov, Summary of the 1st international workshop on environmental, safety and economic aspects of fusion power, Nucl. Fusion 56 (2016) 127001, https://doi.org/10.1088/0029-5515/56/12/127001.

[3] T. Palacios, J. Reiser, J. Hoffmann, M. Rieth, A. Hoffmann, J.Y. Pastor, Microstructural and mechanical characterization of annealed tungsten (W) and potassium-doped tungsten foils, Int. J. Refract. Met. Hard Mater. 48 (2015) 145-149, https://doi.org/10.1016/j.ijrmhm.2014.09.005.

[4] T. Hirai, F. Escourbiac, S. Carpentier-Chouchana, A. Durocher, A. Fedosov, L. Ferrand, T. Jokinen, V. Komarov, M. Merola, R. Mitteau, R.A. Pitts, W. Shu, M. Sugihara, V. Barabash, V. Kuznetsov, B. Riccardi, S. Suzuki, ITER full tungsten divertor qualification program and progress, Phys. Scr. (2014) 014006, https://doi. org/10.1088/0031-8949/2014/T159/014006.

[5] A. Shah Idil, N. Donaldson, The use of tungsten as a chronically implanted material, J. Neural Eng. 15 (2018) 021006, , https://doi.org/10.1088/1741-2552/aaa502.

[6] S.A. Humphry-Baker, W.E. Lee, Tungsten carbide is more oxidation resistant than tungsten when processed to full density, Scr. Mater. 116 (2016) 67-70, https://doi. org/10.1016/J.SCRIPTAMAT.2016.01.007.

[7] S.A. Humphry-Baker, G.D.W. Smith, Shielding materials in the compact spherical tokamak, Philos. Trans R Soc A Math Phys Eng Sci, The Royal Society Publishing, 2019, p. 20170443, , https://doi.org/10.1098/rsta.2017.0443.

[8] A.S. Kurlov, A.I. Gusev, Tungsten carbides and W-C phase diagram, Inorg. Mater. 42 (2006) 121-127, https://doi.org/10.1134/S0020168506020051.

[9] C.M. Fernandes, A.M.R. Senos, Cemented carbide phase diagrams: a review, Int. J. Refract. Met. Hard Mater. 29 (2011) 405-418, https://doi.org/10.1016/j.ijrmhm. 2011.02.004.

[10] G. Mühlbauer, G. Kremser, A. Bock, J. Weidow, W.-D. Schubert, Transition of W2C to WC during carburization of tungsten metal powder, Int. J. Refract. Met. Hard Mater. 72 (2018) 141-148, https://doi.org/10.1016/J.IJRMHM.2017.12.018.

[11] T. Dash, B.B. Nayak, Preparation of WC-W2C composites by arc plasma melting and their characterisations, Ceram. Int. 39 (2013) 3279-3292, https://doi.org/10. 1016/J.CERAMINT.2012.10.016.
[12] S.K. Li, J.Q. Li, Y. Li, F.S. Liu, W.Q. Ao, Dense pure binderless WC bulk material prepared by spark plasma sintering, Mater. Sci. Technol. 31 (2015) 1749-1756, https://doi.org/10.1179/1743284714Y.0000000753.

[13] K. Arshad, J. Wang, Y. Yuan, Y. Zhang, Z.-J. Zhou, G.-H. Lu, Development of tungsten-based materials by different sintering techniques, Int. J. Refract. Met. Hard Mater. 50 (2015) 253-257, https://doi.org/10.1016/J.IJRMHM.2015.02.004.

[14] R.M. German, Lower sintering temperature tungsten alloys for space research, Int. J. Refract. Met. Hard Mater. 53 (2015) 74-79, https://doi.org/10.1016/J.IJRMHM. 2015.04.020.

[15] K.-M. Tsai, C.-Y. Hsieh, H.-H. Lu, Sintering of binderless tungsten carbide, Ceram. Int. 36 (2010) 689-692, https://doi.org/10.1016/J.CERAMINT.2009.10.017.

[16] C. Ren, Z.Z. Fang, H. Zhang, M. Koopman, The study on low temperature sintering of nano-tungsten powders, Int. J. Refract. Met. Hard Mater. (2016), https://doi.org/ 10.1016/j.ijrmhm.2016.10.003.

[17] A. Gubernat, P. Rutkowski, G. Grabowski, D. Zientara, Hot pressing of tungsten carbide with and without sintering additives, Int. J. Refract. Met. Hard Mater. 43 (2014) 193-199, https://doi.org/10.1016/j.ijrmhm.2013.12.002.

[18] S. Deng, T. Yuan, R. Li, F. Zeng, G. Liu, X. Zhou, Spark plasma sintering of pure tungsten powder: densification kinetics and grain growth, Powder Technol. 310 (2017) 264-271, https://doi.org/10.1016/J.POWTEC.2017.01.050.

[19] A. Šestan, P. Jenuš, S.N. Krmpotič, J. Zavašnik, M. Čeh, The role of tungsten phases formation during tungsten metal powder consolidation by FAST: implications for high-temperature applications, Mater. Charact. 138 (2018) 308-314, https://doi. org/10.1016/J.MATCHAR.2018.02.022.

[20] K. Arshad, J. Wang, Y. Yuan, Y. Zhang, Z.J. Zhou, G.H. Lu, Development of tungsten-based materials by different sintering techniques, Int. J. Refract. Met. Hard Mater. (2015), https://doi.org/10.1016/j.ijrmhm.2015.02.004.

[21] E. Tejado, A. Martin, J.Y. Pastor, Effect of Ti and TiC alloyants on the mechanical properties of W-based armour materials, J. Nucl. Mater. 514 (2019) 238-246, https://doi.org/10.1016/j.jnucmat.2018.12.001.

[22] P. Jenuš, A. Iveković, M. Kocen, A. Šestan, S. Novak, W2C-reinforced tungsten prepared using different precursors, Ceram. Int. 45 (2019) 7995-7999, https://doi. org/10.1016/J.CERAMINT.2018.11.187.

[23] S. Chanthapan, A. Kulkarni, J. Singh, C. Haines, D. Kapoor, Sintering of tungsten powder with and without tungsten carbide additive by field assisted sintering technology, Int. J. Refract. Met. Hard Mater. 31 (2012) 114-120, https://doi.org/ 10.1016/J.IJRMHM.2011.09.014.

[24] A. Šestan, J. Zavašnik, M.M. Kržmanc, M. Kocen, P. Jenuš, S. Novak, M. Čeh, G. Dehm, Tungsten carbide as a deoxidation agent for plasma-facing tungsten-based materials, J. Nucl. Mater. 524 (2019) 135-140, https://doi.org/10.1016/J. JNUCMAT. 2019.06.030.

[25] J.A. Escribano, B. Ferrari, P. Alvaredo, E. Gordo, A.J. Sánchez-Herencia, Colloidal processing of Fe-based metalceramic composites with high content of ceramic reinforcement, Bol. La Soc. Esp. Ceram. y Vidr. 52 (2013) 247-250, https://doi.org/ 10.3989/cyv.312013.

[26] M. Dios, Z. Gonzalez, P. Alvaredo, R. Bermejo, E. Gordo, B. Ferrari, Novel colloidal approach for the microstructural improvement in Ti(C,N)/FeNi cermets, J. Alloys Compd. 724 (2017) 327-338, https://doi.org/10.1016/j.jallcom.2017.07.034.

[27] R.G. Neves, B. Ferrari, A.J. Sanchez-Herencia, E. Gordo, Improvement of sintering behaviour of titanium by colloidal techniques, Powder Metall. 56 (2013) 258-262, https://doi.org/10.1179/0032589913Z.000000000117.

[28] A.J. Sanchez-Herencia, A.J. Millan, M.I. Nieto, R. Moreno, Gel-forming of nickel powders from aqueous slurries, Adv. Mater. 12 (2000), https://doi.org/10.1002/ 1521-4095(200008)12:16<1192::AID-ADMA1192 > 3.0.CO;2-0.

[29] J.A. Escribano, B. Ferrari, P. Alvaredo, E. Gordo, A.J. Sanchez-Herencia, Colloida processing of Fe-based metalceramic composites with high content of ceramic reinforcement, Bol. La Soc. Esp. Ceram. y Vidr. 52 (2013), https://doi.org/10.3989/ cyv. 312013.

[30] J.A. Escribano, J.L. Garcia, P. Alvaredo, B. Ferrari, B.E. Gordo, A.J. SanchezHerencia, FGM stainless steel-Ti(C,N) cermets through colloidal processing? Int. J. Refract. Met. Hard Mater. 49 (2015), https://doi.org/10.1016/j.ijrmhm.2014.05. 008.

[31] M. Dios, Z. Gonzalez, E. Gordo, B. Ferrari, Chemical precipitation of nickel nanoparticles on $\mathrm{Ti}(\mathrm{C}, \mathrm{N})$ suspensions focused on cermet processing, Int. J. Refract. Met. Hard Mater. 63 (2016) 2-8, https://doi.org/10.1016/j.ijrmhm.2016.08.009.

[32] R.K. Enneti, Synthesis of nanocrystalline tungsten and tungsten carbide powders in a single step via thermal plasma technique, Int. J. Refract. Met. Hard Mater. 53 (2015) 111-116, https://doi.org/10.1016/J.IJRMHM.2015.06.011.

[33] J.A. Lewis, Colloidal processing of ceramics, J. Am. Ceram. Soc. 83 (2004) 2341-2359, https://doi.org/10.1111/j.1151-2916.2000.tb01560.x.

[34] Y.K. Leong, B.C. Ong, Polyelectrolyte-mediated interparticle forces in aqueous suspensions: molecular structure and surface forces relationship, Chem. Eng. Res. Des. 101 (2015) 44-55, https://doi.org/10.1016/j.cherd.2015.07.001.

[35] A. Bleier, J. Cesarano III, I.A. Aksay, Stability of aqueous alpha-Al2O3 suspensions with poly(methacrylic acid) polyelectrolyte, J. Am. Ceram. Soc. (1988), https://doi. org/10.1111/j.1151-2916.1988.tb05855.x. 